\title{
THE CHARACTER OF INTERDEPENDENCE BETWEEN ISR STRUCTURES FOR LAND UNITS AND THOSE OF AIR AND NAVAL UNITS
}

\author{
Lt.Col. Valeriu Adrian JIANU, PhD Candidate*
}

\begin{abstract}
Connecting ISR structures from Land Units with ISR structures of Air and Naval units, represents a real challenge, for assuring the whole information cycle in a flexible, robust, and complex architecture in order to create a common known image and to assure support for the commander of the Joint Forces Group in taking the best decisions. The importance of achievement interconnection between ISR structures at all level of hierarchy and from all categories of forces is determined by impredictibility of operational environment, and the necessity of shortening response time during decisional process.
\end{abstract}

Keywords: intelligence; reconnaissance; surveillance; Land Forces; Air Forces; Naval Forces; Joint Forces Group.

The constantly changing operational environment, technological developments and unprecedented ISR means made us analyze the possibility of using ISR capabilities in a timely, prioritized manner, in an optimal ISR architecture, to obtain as much information as possible in support of operations, but also to avoid overcrowding with irrelevant, outdated or inaccurate information.

ISR collection capabilities can operate in all operational environments, and can be characterized as terrestrial, airborne, naval, space, cybernetic, environmental. ${ }^{1}$

According to the Explanatory Dictionary of the Romanian language, interdependence means "the connection and mutual conditioning between processes, things, phenomena, etc." 2 . Currently, the effective cooperation of sensors of the Land Forces with the sensors of the Air Force and the Naval Forces, can determine the increase of efficiency of joint operations, by achieving a common objective, in a clearly determined space and period of time.

The execution of military operations in the land, air and naval confrontation environments allows "simultaneous interception of targets and achievement of the recognized common image"3.

The experience of the latest conflicts shows that the success of military operations is determined by the participation of at least two categories of forces. None of them can win alone. An eloquent example

\footnotetext{
*"Carol I" National Defence University e-mail:adi_jianu@yahoo.com
}

of this is the Gulf War in which the Multinational Coalition was organized from structures belonging to all means of confrontation, constituted in a group of joined forces.

The synchronization of means of gathering information from all categories of forces and from all hierarchical levels is an important part of the ISR process. The data and information received from an ISR collection medium in the LF can be supplemented with products received from the other means of collection within the NF or AF.

Starting from the definition of ISR architecture that represents "the totality of organizations, processes, relationships and systems that connect the collection elements, databases, services, applications, analysis structures and beneficiaries in an operational environment" ${ }^{\prime 4}$ we can understand that the interrelation and the inter-connectivity of all sensors in LF, NF and AF, is a subsystem of the entire architectural information system.

Moreover, we can say that the applicability of the principles of ISR architecture management (inter-connectivity, flexibility, compatibility, mission adaptation, centralized control $)^{5}$ is common to all ISR structures in the Land Forces, Naval Forces and Air Forces.

Unlike the specialized collection capabilities in Land Forces (HUMINT, OSINT, IMINT, GEOINT, ACINT, MASINT) ${ }^{6}$, in the Naval Forces we find OSINT, IMINT, SIGINT, RADINT, water location capabilities that include coastal and wide systems, capabilities on CBRN situation, research capabilities within the Marine Regiment and the Naval Group 
of Special Operations Forces ${ }^{7}$. Moreover, through the Joint Doctrine for Intelligence, Surveillance and Reconnaissance, we can complete the list with collection capabilities such as CYBERINT, TECHINT, EW, MPE ${ }^{8}$.

We can observe that, in accordance with the Romanian doctrine, there are some similar collection capabilities, which can determine a high degree of cooperation, but also different collection capabilities that can generate a complete volume of information and implicitly a "comprehensive" overview at meeting level.

From a doctrinal point of view ${ }^{9}$, collection systems can be arranged on the ground, on aerial/ space platforms and on maritime platforms. Electronic and infrared surveillance, electronic optical and radar research and surveillance are common to all three collection systems in the Land, Air and Naval Forces.

Moreover, the collection systems arranged on the aerial platforms have hyper spectral and multi spectral imaging equipment as well as the detection of magnetic anomalies. On the other hand, collection systems arranged on naval platforms include acoustic detection means, such as ground collection systems. Human capabilities (HUMINT) capabilities are obviously specific to ISR structures in the Land Forces.

From the perspective of IMINT (Imagery Intelligence $)^{10}$ the platforms carrying sensors (image capture and analysis) are terrestrial, airborne and naval.

From a terrestrial point of view, we can talk about static platforms (lighthouses, towers or even higher gazebos), which are marked and visible to ensure area air management, but nevertheless have low visibility possibilities. We can also talk about mobile platforms, less known and called unmanned ground vehicles (UGVs), which can provide shortdistance images; these are not expensive, but can be easily captured, or may be damaged during the mission.

On the other hand, the aerial platform ${ }^{11}$ can be with or without human crew on board. Crewed platforms can fly at high altitudes, over long distances, with very good autonomy and can transmit photos, recordings and data in almost real time, but they have the disadvantages of the risk of losing crew members and are very expensive. Unmanned platforms have the advantage that they do not take the risk of crew losses, they can transmit photos and recordings in almost real time, they can be used several times, they are operated from the ground, but they must be included in the air control system. Both aerial platforms depend on weather conditions.

The UAS control station can be installed on land, naval and air forces; it ensures the planning and execution of missions, implements the communications system, ensures the processing, exploitation and dissemination of information to beneficiaries ${ }^{12}$.

Naval platforms can provide images both from the marine environment and from coastal or port areas and these can complement the "recognized common picture". Naval platforms can be with human crew on board or without human crew on board. Naval platforms without human crew on board can be surface, semi-submersible, or underwater (autonomous or remotely controlled by an operator). The mobile aerial platforms may be launched from ships with human crew on board ${ }^{13}$.

The supervision of the operations area by sensors ensures the informational supremacy over the opponent as well as the possible adaptation of the operations to complex situations, of the mode of action, but especially of the imposition of one's own will ${ }^{14}$.

According to specialists in the field ${ }^{15}$, surveillance by observation of air, land and naval space is performed for the execution of the mutual exchange of data and information by identifying and reporting the main characteristics of land, air and naval means, as well as the modalities of action and of executed maneuvers.

Also, the landing places of the sea and air landing elements, used by the opponent of the CBRN means, are determined, the evaluation of anti-aircraft strikes is performed, as well as the observation and reporting of meteorological phenomena and climate changes in the area of operations.

The exchange of information between ISR structures of Land Forces and ISR structures of Air Force obviously contributes to the mutual support of the two categories of forces in the joint operation. However, for the efficiency of air support against the opponent and for the success of joint operations, a number of factors must be taken into account ${ }^{16}$ such as weather conditions, terrain, 
tactical rules of joint operation areas, difficulties encountered during ground transport, the existence of airports in the area of joint operations.

In order to carry out the air denial operation on some targets (usually fixed) from the depth of the adversary combat layout, an operation that requires deliberate planning, ISR structures from the Land Forces can infiltrate the adversary combat layout. After infiltration, they can provide vital information about the adversary such as command points, elements of logistics system, sectors, phase lines, as well as the effects of blows on the adversary (battle damage assessment).

The infiltration of ISR elements from Land Forces into the depths of the opponent's combat layout can be achieved both with the support of Naval Forces and with the support of Air Force. Infiltration with the support of the Naval Forces is carried out with the help of surface ships or by immersion, and infiltration with the help of the Air Force is carried out by parachuting or landing.

Both processes have advantages and disadvantages depending on many factors such as: operation type, adversary disposal, time and fighting area. Moreover, the ISR structures of Land Forces are obliged, in my opinion, to have specialized personnel such as paratroopers, divers and specialized personnel for the elementary navigation necessary for landing in both hostile and less hostile areas.

Within the ISR system of the Naval Forces, the processing, integration and dissemination to authorized beneficiaries of the "recognized unique naval image" is carried out through the Integrated Black Sea Research and Observation System (SCOMAR). ${ }^{17}$ The system can ensure the transfer of information to all the hierarchical levels (strategic, operative and tactical) from the Naval Forces and, if necessary, to other categories of forces from the Romanian Army.

Through this system, situational awareness is achieved both from a naval and aerial point of view, as well as for avoiding strategic surprise and ensuring indices and early warning. The system ensures the exchange of information regarding the identification of partners/opponents, the discovery of surface ships and submarines, air targets but also the situation in the electromagnetic spectrum.

According to some military specialists ${ }^{18}$, radar, lidar and sonar represent sensors with "the highest applicability in aerial surveillance and detection of moving bodies in terrestrial, maritime and aerial environments".

The ISR Structures of Land Forces may cooperate with the ISR Structures of Naval and Air Force in the field of open source information (OSINT). Open source information can be complementary to other collection disciplines, can confirm certain data, can significantly contribute to the joint preparation of operational environment information (JIPOE).

At a joint level, OSINT can provide information about the adversary capabilities, intentions, locations, characteristics of the environment from the social, political, economic, military and cultural point of view in which the operation takes place. Also, by monitoring all open sources, ISR structures specialized in OSINT can contribute to the identification of indices and the issuance of warnings about threats to the security environment. At the same time, they can contribute to the targeting process (identification and prioritization of targets), as well as to the evaluation of losses in operation and avoidance of collateral damage ${ }^{19}$.

In this sense, the speed of collection and transmission of information by ISR structures and especially the dissemination to the beneficiary is important. Coordination is accomplished through Intelligence Requirement Management and Collection Management (IRM\&CM), so that information collected from open sources by ISR structures in the Land Forces can reach both the Air Force and the Navy in a timely manner and vice versa.

For the mutual connection of sensors in LF, AF and NF in terms of unclassified information, certain Internet networks can be used such as: World Wide Web, Deep Web, Dark Web.

On the World Wide Web the connection is made using a standard code called HTML/Hyper-text Mark-up Language. On the Deep Web the network content is not accessible through standard common search engines, includes private sites, involves subscribing and registering operators. The Dark Web is a component of Deep Web, it is intentionally hidden and only accessible through encrypted networks ${ }^{20}$.

Another means of interconnection could be a tactical secured data network, called Internet Protocol/IP. In NATO, it is called the NATO 
General Communications System (NGCS) which consists of NATO systems and subsystems at all hierarchical levels. For securing the network and avoiding sharing to unauthorized persons, NGCS is accessorized with an encryption device to limit access to information, called a "boundary protection device" ${ }^{21}$.

A system used within NATO that proves its effectiveness today through theatre of operations, which can be used by ISR structures is "Blue Force Tracking". This assures the connection of all "blue forces" in an area of operations, is interoperable and can provide a complete picture of the disposition of its own and allied forces and contributes decisively to the avoidance of fratricide.

In the American doctrine ${ }^{22}$ we find the concept of "Distributed Common Ground System" (Army/ DCGS-A). The system provides decision makers with the ability to receive data and information from the field but also to send messages, tasks, information to all sensors in the area of operations. The system also meets the information requirements at all hierarchical levels.

In the future, it is necessary to adhere to a common data link management strategy within NATO (NATO Bi-Strategic Commanders Data) Link Management Strategy/Bi-SC DLMS). This is useful in order to improve automatic link management, to reduce duplication of information, to design a common message format, to standardize reporting ${ }^{23}$.

\section{Conclusions}

The interconnection of ISR structures of Land Forces with the ISR structures of the Air and Naval Forces, can be essential in the information support of the Joint Forces Group and can contribute decisively to the success of any operation.

I believe that it is necessary to continue in this direction of research, because it has represented, represents and will represent a real challenge for the coming future. We have to admit that the interconnectivity to all sensors is difficult to realize. The topic is a reason for debate not only for the Romanian Army but also for other NATO member armies.

Working with information in a collaborative environment, with a high level of interconnection, with obeying two principles that have become classic, "the need to know" and "the need to distribute", we can avoid the appearance of vital information that will be much delayed.

I believe that we need to train more together, experience more information exchange, and understand, as history has shown countless times, that a decision made today (even if is not the best) is much more valuable than a decision taken tomorrow but too late.

The experience can be gained by intensifying joint exercises between ISR structures belonging to all categories of forces in the Romanian Army, increase cooperation, interconnection and why not, even of mutual trust.

\section{NOTES:}

1 I.A.-1.5 Joint Doctrine for Information, Surveillance and Research, Bucharest, 2017, p. 38.

2 Romanian Explicative Dictionary, accessed on 05.04.2021.

3 Cristian Stanciu, The physiognomy of military operations in the contemporary security environment, "Carol I" National Defence University Publishing House, Bucharest, 2016, p.70.

4 I.A.-1.5, Ibidem, p. 43.

5 I.A.-1.5, Ibidem, p. 39.

6 SMFT-20, Manual for the use of SRI elements in the Land Forces, Bucharest, 2019, p. I-3.

7 F.N.-1.3, Doctrine for operations of the Naval Forces, Bucharest, 2012, art. 30.

8 I.A.-1.5, op.cit, p. 15.

9 I.A.-1.5, Ibidem, pp. 10-11.

10 I.A.-2.6, Doctrine of support with military information obtained by exploiting IMINT images, Bucharest, 2013, p. 36.

11 I.A.-2.6, op.cit., p. 37.

12 SMAp-2 Military Manual for the use of unmanned aircraft systems (UAS) in the Romanian Army, Bucharest, 2021, p. 8.

13 I.A.-2.6, Ibidem, p. 46.

14 Radu D. Ghica, "Typology of missions in the conditions of the new operational environment at the beginning of the 21st century", CSSAS, Policies and strategies in conflict management, "Carol I" National Defence University Publishing House, Bucharest, 2008, p. 39.

15 F.A.1.1.3.2. Manual on the organization and execution of surveillance by observation of air and ground / maritime space in the General Staff of the Air Force, Bucharest, 2011, p. 8.

16F.A./Av-2,Air Fleet Combat Manual, Bucharest,2010, p. 24.

17 F.N.-1.3, Doctrine for Operations of the Naval Forces, Bucharest, 2012, art. 9.

18 Petru Pîrjol, The architecture of the airspace surveillance system. Structural and functional dynamics, "Carol I" National Defence University Publishing House, 2020, p. 37.

19 I.A.-1.7 Doctrine for open source information, Bucharest, 2020, p. 15. 
20 I.A.-1.7, Ibidem, p. 27.

21 FA-1.2, Doctrine on air defence and ground-based missile defence, Bucharest, 2020, p. 17.

22 FM 2.0. Intelligence, Headquarters, Department of the Army, Washington DC, 2004, p. I-23.

23 FA-1.2, Ibidem, p.18.

\section{REFERENCES}

*** AJP- 2.7 Allied Joint Doctrine for Reconnaisannce and Surveillance, 2009.

*** AJP-3.2 Allied Joint Doctrine for Land Operations, 2016.

*** AJP-3.3 Allied Joint Doctrine for Air and Space Operations, 2016.

*** F.A.1.1.3.2., Manual on the organization

and execution of surveillance by observation of air and land/maritime space in the Air Force General Staff, Bucharest, 2011.

*** F.A.1.2., Doctrine on ground-based air

and missile defence, Bucharest, 2020.

*** F.A./Av-2, Manual for the combat of the

air flotilla, Bucharest, 2010.

*** FM 2.0. Intelligence, Headquarters,

Department of the Army, Washington DC, 2004.

*** F.N.-1.3, Doctrine for operations of the

Naval Forces, Bucharest, 2012.

*** I.A-1.5, Joint Doctrine for Information,

Surveillance and Research, Bucharest, 2017.

*** I.A-1.7, Doctrine for open source information, Bucharest, 2020.
*** I.A.-2.6, Doctrine of support with military information obtained by exploiting IMINT images, Bucharest, 2013.

*** IGEO-1, Instructions on geospatial support in the Romanian Army, Bucharest, 2020.

*** SMAp-2 Military Manual for the use of unmanned aircraft systems (UAS) in the Romanian Army, Bucharest, 2021.

*** SMAp-74, Doctrine of operations in cyberspace, Bucharest, 2020.

*** SMFT-20, Manual for the use of SRI elements in the Land Forces, Bucharest, 2019.

*** Romanian Explicative Dictionary,

dexonline.ro

Ghica Radu D., "Typology of missions in the conditions of the new operational environment at the beginning of the 21st century", CSSAS, Policies and strategies in conflict management, "Carol I" National Defence University Publishing House, Bucharest, 2008.

Pîrjol Petru, The architecture of the airspace surveillance system. Structural and functional dynamics, "Carol I" National Defence University Publishing House, Bucharest, 2020.

Stanciu Cristian, The physiognomy of military operations in the contemporary security environment, "Carol I" National Defence University Publishing House, Bucharest, 2016. 